\title{
Evaluating web accessibility of educational institutions websites using a variable magnitude approach
}

\author{
K. S. Kuppusamy ${ }^{1}$ (I) $\cdot$ V. Balaji ${ }^{1}$
}

Accepted: 8 April 2021 / Published online: 7 May 2021

(c) The Author(s), under exclusive licence to Springer-Verlag GmbH Germany, part of Springer Nature 2021

\begin{abstract}
The World Wide Web serves as an excellent platform for information dissemination. Educational institutions such as universities are utilizing the web medium to reach their target audience. In the post-Covid-19 scenario, the web medium has obtained increased significance as it has become the primary access channel to reach these institutions. In this backdrop, it becomes essential to analyze the accessibility of these sites for students with special needs. This paper presents an approach to compute the accessibility of web pages for persons with disabilities. A variable magnitude approach is proposed in this paper for the computation of accessibility barrier count as a combination of two different components. The proposed approach is experimented with top ranked higher educational institution websites of India. Based on the inferences from the results and inputs received from students with disabilities, a set of suggestions have been compiled by this paper to minimize the barriers faced by persons with disabilities in consuming these web resources.
\end{abstract}

Keywords Web accessibility $\cdot$ WCAG $\cdot$ Accessibility score $\cdot$ Variable magnitude approach

\section{Introduction}

The prolific expansion of World Wide Web (WWW) has positioned it as an important platform to reach large number of users instantly. The spectrum of services that are running on the web is unprecedented in nature. The World Wide Web is rendering various services such as banking, e-commerce and educational services. Global reach through a wide spectrum of devices constitutes the uniqueness of the web.

Though the World Wide Web has its reach at the global scale, it shall pose barriers to specific group of users such as persons with disabilities, if not designed properly. As envisaged by the inventor of the web Sir Tim Berners Lee, the World Wide Web should remain a platform which shall be utilized by everyone irrespective of their physical disabilities ${ }^{1}$.

The World Wide Web has been in active use for the past few decades. However, with the onset of Covid-19

\footnotetext{
K. S. Kuppusamy

kskuppu@gmail.com

V. Balaji

balajipucs@gmail.com

1 Department of Computer Science, School Of Engineering and Technology, Pondicherry University, Pondicherry, India
}

pandemic, the global scenario has mutated into a new dimension. Earlier, in many cases, the web was utilized as an ancillary channel of service delivery. But in the post Covid19 scenario, the World Wide Web has become the primary channel of service delivery. In such a scenario, it becomes critical to maintain the web channel of access in a barrierfree manner for all groups of users which certainly includes persons with disabilities.

In the post-Covid-19 scenario, educational institutions across the globe have resorted to the web channel of access. The primary access to educational institutions such as universities is now through their official websites. All of the critical information such as admission-related information, course materials dissemination, examination-related information is provided to both the currently enrolled students and the potential students through the university websites.

The World Health Organization has stated that $15 \%$ of the world population is experiencing some sort of disabilities, which scales up to 1 billion $^{2}$. In other words, one in seven persons in the global population has some sort of disabilities. This significant chunk of human population should not

\footnotetext{
$\overline{1}$ https://www.w3.org/standards/webdesign/accessibility.

2 https://www.who.int/teams/noncommunicable-diseases/disabilityand-rehabilitation/world-report-on-disability.
} 
Table 1 Population of persons with disabilities rural and urban (in millions)

\begin{tabular}{llll}
\hline Residence & Male & Female & Total \\
\hline Urban & 8.2 & 3.6 & 11.8 \\
Rural & 10.4 & 4.6 & 15.0 \\
Total & 18.6 & 8.2 & 26.8 \\
\hline
\end{tabular}

be left facing barriers in accessing these critical information resources.

With respect to the Indian context, the official census statistics of 2011 states that 26.8 million persons are experiencing some sort of disabilities, as shown in Table 1. It shall be observed from Table 1 that out of 26.8 million population, 15.0 million people are from the rural regions. It puts an increased emphasis that while designing the web pages, the bandwidth requirements of this population also need to be taken into consideration.

The Government of India has been running missioncritical projects such as Digital India ${ }^{3}$ and Accessible India ${ }^{4}$. The primary objective of Digital India is to facilitate providing the services through the digital ecosystem. The accessible India campaign aims to enable the persons with disabilities by providing them a barrier-free environment across three dimensions, including built-environment, transportation and cyberspace. This paper deals with one of the components of cyberspace accessibility, i.e., website accessibility.

India has a demographic advantage of youth population. This ratio holds in persons with disabilities as well. Accessibility of both physical infrastructure and that of digital infrastructure are two major factors determining the educational choices of students with disabilities. In this study, the focus is on one of the important components of cyber infrastructure, i.e., the websites which serves as an entry point of information and access. As the current study is focusing on students with disabilities, the percentage of students under each category of disability is as shown in Table 2.

It shall be observed from Table 2 that there exists a significant portion of students under each types of disabilities. In order to cater to the needs of these students, it becomes mandatory that the access to the websites should be made barrier-free to build an inclusive ecosystem for students with disabilities. Information technology and its associated tools are serving as a great enabler to students with disabilities. In that respect, websites also serve as an easier channel of information access for students with disabilities. However, the need for designing websites with proper accessibility

\footnotetext{
3 https://www.digitalindia.gov.in/.

${ }^{4}$ http://accessibleindia.gov.in/content/.
}

Table 2 Proportion of categorywise students with disabilities

\begin{tabular}{ll}
\hline Disability type & $\begin{array}{l}\text { Percentage } \\
\text { of students }\end{array}$ \\
\hline Persons with visual impairments & 28.0 \\
Persons with hearing impairments & 32.5 \\
Persons with speech impairments & 37.2 \\
Persons with loco-motor impairments & 19.7 \\
Persons with mental retardation & 24.5 \\
Persons with mental illness & 9.3 \\
Persons with other forms of disability & 37.4 \\
Persons with multiple disabilities & 15 \\
\hline
\end{tabular}

features becomes paramount important. With the recent launch of Self Reliant India project, it is absolutely necessary that this significant population of the country should be made self-reliant and for that reason education is an important enabler. To make persons with disabilities self-reliant, providing a barrier-free web ecosystem is essential.

Though the aforementioned statistics are provided for the Indian scenario, the requirements of students with disabilities at the global scenario also remain similar.

\subsection{Inclusion is the key}

One of the important advantages of the web is the ability to reach a wider spectrum of audience with diverse abilities. With the prolific expansion of digital platforms that enabled different educational approaches, it becomes mandatory to keep the web resources fully accessible to persons with disabilities.

The first step in achieving this target is to make the web pages of the educational institutions fully accessible to persons with disabilities. To make the pages accessible, the barriers which are currently posed by these pages need to be measured. If we need to enhance something, then the current status needs to be measured first. In that perspective, the web accessibility barrier measurement of educational websites gains significance.

In this paper, the critical tasks of measuring the barriers rendered by web pages in terms of accessibility are given primary importance. Inclusion is the key to make the every learner feel comfortable and empowered.

The major objectives of this paper are as listed below:

- To propose a variable magnitude approach to compute the accessibility barrier count;

- To evaluate the web accessibility of the top ranked educational institution websites with the proposed score;

- To provide a list of suggestions to make the web pages of educational institutions such as universities, barrier-free for students with disabilities. 
The remainder of this paper is organized as follows: motivational works which have led to the conduct of this study are presented in Sect. 2. Popular accessibility evaluation tools are explored in Sect. 3. The web accessibility barrier computation procedure along with the mathematical and algorithmic representations is provided in Sect. 4. The web accessibility analysis of websites is provided in 5. Potential suggestions to improve the web accessibility of educational institution websites are given in Sect. 6. Conclusions and future directions are addressed in Sect. 7.

\section{Motivational works}

Accessibility Computing has evolved into an active research area which falls under the Human Computer Interaction Domain [4]. This domain majorly focuses on empowering the persons with disabilities by using technology as an enabler [20]. The primary advantage of using technology as an enabling tool is that it reduces the dependency on human assistance which might not be available at all times. Moreover, technology can be replicated to reach a large number of people once its development is completed. Accessibility analysis is the primary objective of this paper. Accessibility analysis has been carried out by various research groups across the globe $[1,3,7,9,10,12,19,21,30,33]$.

Analyzing the educational institution websites has also been explored by various research studies $[2,5,14-17,26$, 32]. There are studies conducted on library websites of educational websites focusing on accessibility [23]. These studies have focused on a group of websites belonging to a particular country or geographical regions. There are some studies which have focused on the leading universities of the world $[6,18]$.

There are studies which have focused on longitudinal comparison of results. One of the important studies in this domain is conducted with a longitudinal analysis which has compared the accessibility status of universities between 2005 and 2015 [6]. Studies have been conducted on the evaluation of readability which is also a factor in enhancing content accessibility [24].

India-specific web accessibility analysis has also been carried out either focusing at specific websites under a university or under a region or of a particular type [21, 22]. Apart from educational websites, there are accessibility studies available for other sites such as tourism and studies on specific applications to assist persons with disabilities [11,28].

In addition to website accessibility analysis on desktop and laptop browsers, there are studies which have focused on the accessibility of the mobile web [8,29]. As mobile devices have become increasingly popular, these studies
Table 3 Web accessibility evaluation tools

\begin{tabular}{llll}
\hline Tool name & URL & Open source & $\begin{array}{l}\text { Browser } \\
\text { plugin sup- } \\
\text { port }\end{array}$ \\
\hline AChecker & $\begin{array}{c}\text { https://achecker. } \\
\text { ca/checker/ } \\
\text { index.php } \\
\text { https://wave. } \\
\text { webaim.org/ }\end{array}$ & Yes & No \\
WAVE & No & Yes \\
\hline
\end{tabular}

address the specific requirements of users who utilize mobile devices [25, 27, 31].

Accessibility has also been studied along with the cyber security combination as well. These studies focus on specific problems and how they can affect persons with disabilities navigating the cyberspace [13].

It shall be inferred from the aforementioned discussions that the web accessibility analysis has become an important research issue which has been addressed by researchers across various countries. However, there are still many unsolved issues and due to the mammoth number of websites, accessibility remains a relevant problem. This paper has also attempted to take a small step toward contributing to the study of web accessibility by proposing a variable weight approach to compute the accessibility barrier score and to suggest the enhancements to make these resources barrier-free.

\section{Accessibility evaluation tools}

To perform accessibility evaluation of web pages, there exist an array of tools ${ }^{5}$. In this paper, the following two tools as shown in Table 3 are adapted to fetch the accessibility level of components and thereby to build an integrated score.

The primary reason for selecting these two tools is that they provide evaluation results in a structured manner. Another reason is the ability to interact with these tools through programmatic interfaces such as APIs (application programming interfaces).

When accessed through a web browser, the interface provided by these tools has the feature to enter an URL and get the results. The screenshots of AChecker and WAVE tools are as shown in Figure 1 and Figure 2.

The AChecker tool can be configured in the local system also. WAVE provides a browser plugin using which the accessibility analysis of the current page can be carried out.

\footnotetext{
5 https://www.w3.org/WAI/ER/tools/.
} 


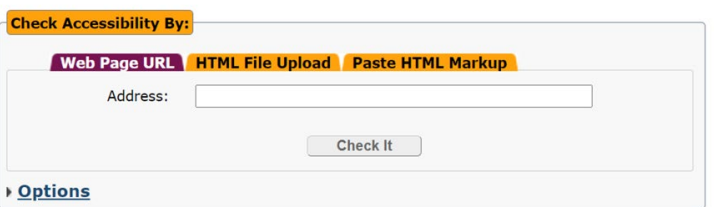

Fig. 1 Screenshot of AChecker

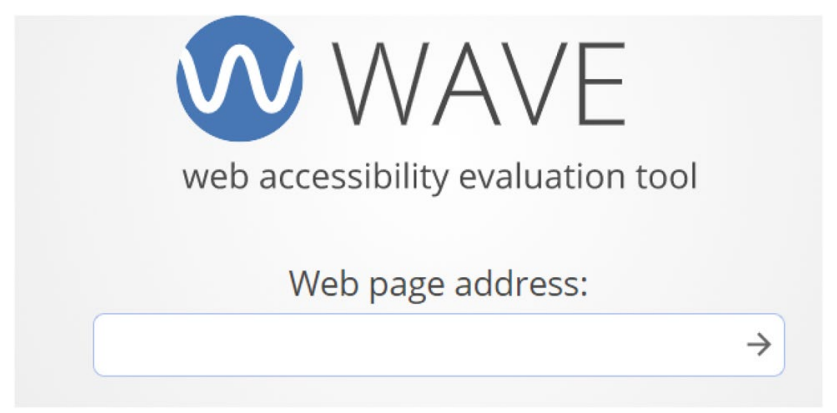

Fig. 2 Screenshot of WAVE tool

\section{Accessibility barrier computation}

This paper proposes a method to compute the accessibility barrier count of a web page. The accessibility barrier count is computed as a combination of two different scores. The first score is based on the evaluation components returned by AChecker, and the second is based on evaluation components returned by WAVE. The accessibility barrier count indicates the magnitude of accessibility errors posed by the web page for persons with disabilities.

\subsection{Accessibility barrier count-AC}

The URL of the web page for which accessibility barrier count is to be computed is passed as input to the AChecker. The rule set selected is Web Content Accessibility Guidelines (WCAG 2.0) with Level $\mathrm{AA}^{6}$. The output from AChecker consists of three components as shown in Eq. 1.

$\Pi=\{\kappa, \lambda, \mu\}$

In Eq. 1, $\kappa$ indicates the Known Errors, $\lambda$ indicates Likely Errors and $\mu$ refers to Potential Errors. This model approaches the computation of accessibility barrier with a

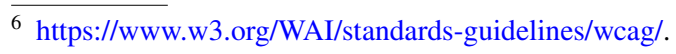

variable magnitude approach. The severity of errors $(\Phi)$ is in the descending order of magnitude as shown in Eq. 2.

$\Phi[\kappa] \geq \Phi[\lambda] \geq \Phi[\mu]$

To factor this into the computation of accessibility barrier, three different weight coefficients $\omega_{k}, \omega_{l}, \omega_{p}$ are introduced.

The $\kappa$ is multiplied by the weight coefficient as shown in Eq. 3.

$\rho_{1}=[\kappa] * \omega_{k}$

The weight coefficient for likely errors is scaled-down with the severity factor $\epsilon$, as shown in Eq. 4 .

$\omega_{l}=\omega_{k} * \epsilon$

The $\lambda$ is multiplied by the weight coefficient as shown in Eq. 5.

$\rho_{2}=[\lambda] * \omega_{l}$

Similarly, the severity factor for potential errors is further scaled down and multiplied by weight vector, as shown in Eq. 6 and Eq. 7.

$\omega_{p}=\omega_{l} * \epsilon$

$\rho_{3}=[\mu] * \omega_{p}$

All of these three components are summed up to generate the score $\left(\rho_{A C}\right)$, as shown in Eq. 10.

$\rho_{A C}=\sum_{i=1}^{3} \rho_{i}$

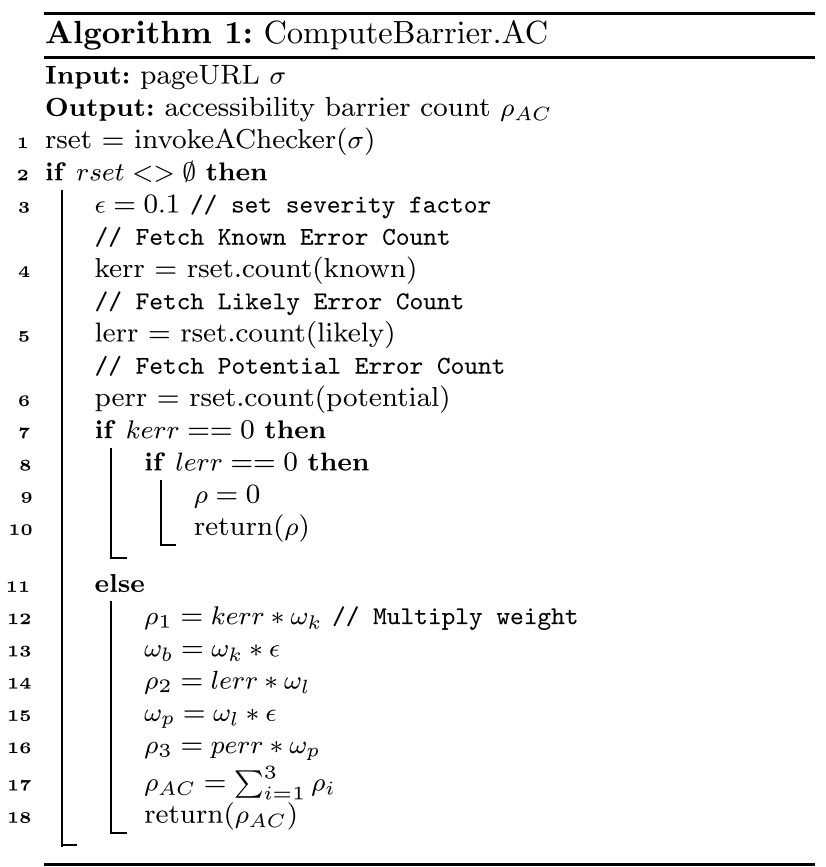


The procedure ComputeBarrier.AC to compute $\rho_{A C}$ is listed in Algorithm 1.

\subsection{Accessibility Barrier Count: WA}

The computation of accessibility barrier count: WA $\left(\rho_{W A}\right)$ is based on the two important components returned by WAVE. These two components are Errors and Contrast Errors. Similar to the AChecker-based barrier computation, WAVEbased barrier computation also involves variable weights and severity factor. The score $\left(\rho_{W A}\right)$ is computed as shown in Eq. 9.

$\rho_{W A}=\left(\left(\gamma * \omega_{e}\right)+\left(\delta * \omega_{c} * \epsilon\right)\right)$

The procedure ComputeBarrier.WA to compute the score is shown in Algorithm 2.

The overall accessibility barrier count score $(\rho)$ is computed using Eq. 10. Here $\omega_{A C}$ and $\omega_{W A}$ indicates the weight coefficients which enables a variable magnitude approach. In case where the score is to computed as the mathematical average, then these weight coefficients shall be initialized to one.

$\rho=\frac{\left(\left(\omega_{A C} * \rho_{A C}\right)+\left(\omega_{W A} * \rho_{W A}\right)\right)}{2}$

The complete procedure to compute the accessibility barrier count score $(\rho)$ is shown in Algorithm 3.

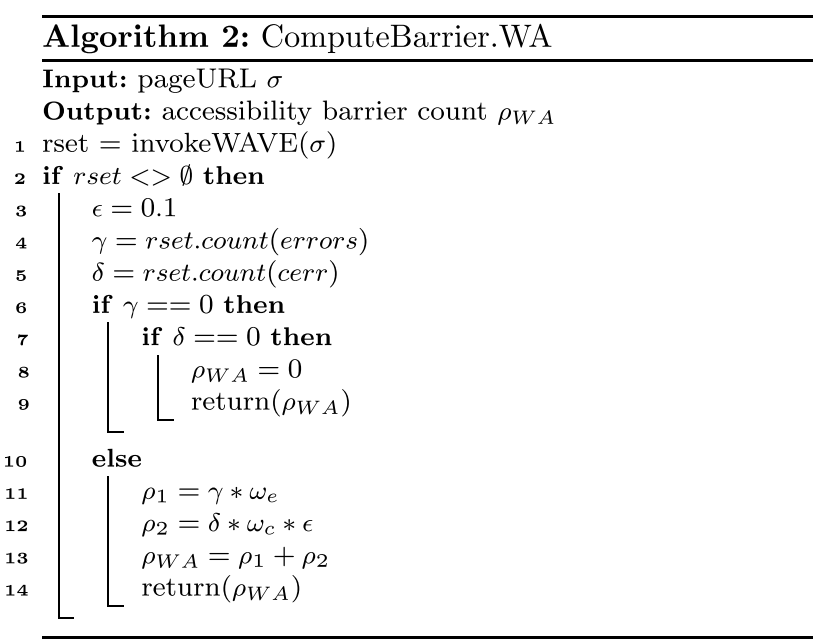

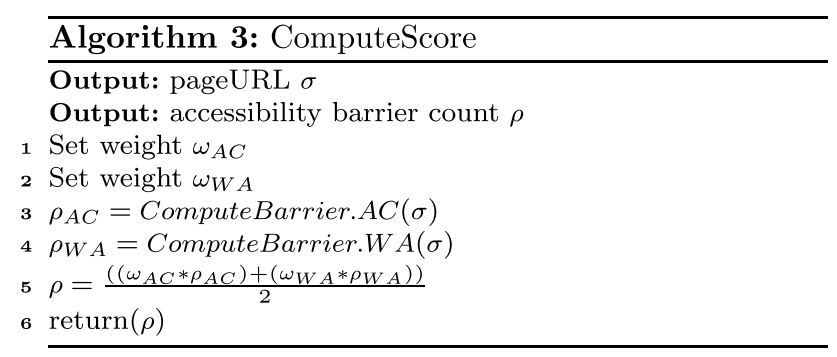

\section{Accessibility analysis}

As this paper focuses on the educational web domains, experiments were conducted the homepages of Top 25 Indian institutions websites taken from NIRF (National Institutional Ranking Framework) 2020 ranking $^{7}$. The URLs of these websites are listed in Table 4

The computation of $\rho_{A C}$ was carried out using the ComputeBarrier.AC procedure, and the results are shown in Table 5.

An illustration of the score in the form of a circle packing chart is provided in Figure 3. The bigger the radius of the circle, the greater is the barrier score. The corresponding website IDs are provided inside the circle for easier reference.

The computation of $\rho_{W A}$ was carried out using the ComputeBarrier.WA procedure, and the results are shown in Table6. The circle packing chart illustration of the analysis is presented in Figure 4. The overall accessibility barrier count $(\rho)$ is computed as per Algorithm 3 (Table 7).

The circle packing chart illustration of the overall score $(\rho)$ is given in Figure 5.

\section{Accessibility enhancement suggestions}

In this section, a list of suggestions are provided to enhance the accessibility of the web pages. These suggestions are derived based on the feedback received from students with disabilities and the inferences from the web accessibility analysis.

- Text Alternatives: One of the important elements of web accessibility is the presence of text alternatives for non-

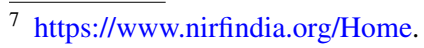


Table 4 Top 25 institution home page URLs

\begin{tabular}{ll}
\hline Rank & URL \\
\hline 1 & https://www.iisc.ac.in/ \\
2 & https://www.jnu.ac.in/main/ \\
3 & https://www.bhu.ac.in/ \\
4 & https://www.amrita.edu/ \\
5 & http://www.jaduniv.edu.in/ \\
6 & https://www.uohyd.ac.in/ \\
7 & https://www.caluniv.ac.in/ \\
8 & https://manipal.edu/mu.html \\
9 & http://www.unipune.ac.in/ \\
10 & https://www.jmi.ac.in/ \\
11 & http://www.du.ac.in/du/ \\
12 & https://www.annauniv.edu/ \\
13 & https://www.b-u.ac.in/ \\
14 & http://www.hbni.ac.in/ \\
15 & https://www.bits-pilani.ac.in/ \\
16 & https://vit.ac.in/ \\
17 & https://www.amu.ac.in/ \\
18 & https://www.ictmumbai.edu.in/ \\
19 & https://www.andhrauniversity.edu.in/ \\
20 & https://www.soa.ac.in/ \\
21 & http://jamiahamdard.edu/ \\
22 & https://www.unom.ac.in/ \\
23 & https://www.keralauniversity.ac.in/ \\
24 & https://kiit.ac.in/ \\
25 & https://www.sastra.edu/ \\
\hline &
\end{tabular}

textual contents such as images, animations. If such a textual description is not available, then it would be very difficult for the students with disabilities to understand the contents of such non-textual resources. Hence, leaving out any images used for decorative purposes, all other elements need to be assigned a textual description so that it would be barrier-free for students with disabilities who are consuming these contents through screen reader in an aural mode;

- Providing Text-Based PDFs: Websites includes resources such as PDF (portable document format) files. Particularly in educational institution websites these files are used to distribute information, learning resources, etc. When uploaded as image-based pdfs by simply scanning hard copy resources, they would not be read properly by screen readers. It would be optimal for screen reader users when the text-based pdfs are utilized which can be read using a screen reader;

- Keyboard-only Navigation: For persons with visual impairments navigating, the web pages through mouse movements are not feasible. Hence, they depend on the keyboard based navigation. The focus would shift from one element to another when the $T a b$ key is pressed. If
Table 5 Computation of $\rho_{A C}$

\begin{tabular}{|c|c|c|c|c|}
\hline ID & Known & Likely & Potential & $\rho_{A C}$ \\
\hline 1 & 3 & 0 & 496 & 7.96 \\
\hline 2 & 42 & 1 & 246 & 44.56 \\
\hline 3 & 1342 & 6 & 1136 & 1353.96 \\
\hline 4 & 30 & 0 & 825 & 38.25 \\
\hline 5 & 14 & 0 & 441 & 18.41 \\
\hline 6 & 34 & 6 & 404 & 38.64 \\
\hline 7 & 20 & 1 & 474 & 24.84 \\
\hline 8 & 54 & 0 & 825 & 62.25 \\
\hline 9 & 27 & 5 & 396 & 31.46 \\
\hline 10 & 62 & 0 & 658 & 68.58 \\
\hline 11 & 507 & 0 & 0 & 507 \\
\hline 12 & 18 & 0 & 148 & 19.48 \\
\hline 13 & 37 & 0 & 730 & 44.3 \\
\hline 14 & 12 & 0 & 20 & 12.2 \\
\hline 15 & 14 & 0 & 1085 & 24.85 \\
\hline 16 & 46 & 5 & 707 & 53.57 \\
\hline 17 & 56 & 1 & 803 & 64.13 \\
\hline 18 & 376 & 0 & 0 & 376 \\
\hline 19 & 101 & 2 & 919 & 110.39 \\
\hline 20 & 28 & 0 & 0 & 28 \\
\hline 21 & 515 & 36 & 1971 & 538.31 \\
\hline 22 & 80 & 3 & 515 & 85.45 \\
\hline 23 & 89 & 0 & 664 & 95.64 \\
\hline 24 & 68 & 1 & 935 & 77.45 \\
\hline 25 & 12 & 0 & 642 & 18.42 \\
\hline
\end{tabular}

the focus order is maintained properly, then this navigation through keyboard would be made much simpler. This option would be very much useful not only for persons with visual impairments but also for persons who have difficulty in controlling the mouse movements because of various physical conditions;

- Custom Color Contrast: One of the important attributes of accessibility is that it does not follow a one-size-fitsall model. The needs of various users would be different based on their specific requirements. Keeping this in mind, adjusting the color contrast based on the user preference is one of the important factors. Many websites have provided such a feature to adjust text-size and color contrast. Wherever they are absent, these features shall be added so that the persons with disabilities can tune it as per their specific requirements. It shall also be selected based on the devices that they are using for browsing the web pages. On a smaller sized display, text size and contrast requirements would be different from a bigger display. It can be different based on ambient lighting conditions, etc.

- Proper Structuring of Forms: In web pages, Forms are the mechanism to receive user input. In such a scenario, 
Fig. 3 Circle packing chart of accessibility barrier count: AC

proper labelling of form elements, placement and size of the elements shall also be kept at a comfortable level so that persons with disabilities can interact with the contents in a seamless manner;

- Multimodal alerts: Indicating alerts with a specific representation such as color is not accessible for persons with visual impairments. For example, in some scenarios green is used to indicate success and red color is used to indicate failure of an operation. This form of color only alert mechanism is inaccessible. In these circumstances, alternative ways of alerts such as audio, textual and haptics shall be incorporated to enhance accessibility of web resources for persons with disabilities;

- Multimedia Accessibility: The multimedia components shall be better accessible, if the following features are added: Captions should be made compulsory for all videos so that persons with hearing impairments shall understand the audio contents of the video. Similarly, audio descriptions about the happenings of the video shall be provided so that persons with visual impairments can completely understand such contents;

- Multilingual accessibility: When web pages are translated from one language to another, the alt-text should be given enough focus so that in the target language also it is able to give the proper description. As the alt-text is shorter in nature, translation from one language to another needs to be done precisely so that persons with disabilities who are depending only on it would be able to get the correct meaning based on the context;

- Accessible Learning Materials: The most important advantage of digital learning materials is that if designed properly, they can be accessed by persons with disabilities in a better manner comparing the physical paperbased resources. Some of the important guidelines are as follows:

- Ensuring proper heading structure of the documents so that the screen reader users can navigate in an effective manner;

- Table headers need to be given in a semantic manner so that understanding becomes easier;

- Placement of floating boxes shall be avoided so that the reading order can be maintained properly;

- In case of links in the documents proper hyperlinks text should be placed; 
Fig. 4 Circle packing chart of accessibility barrier count: WA

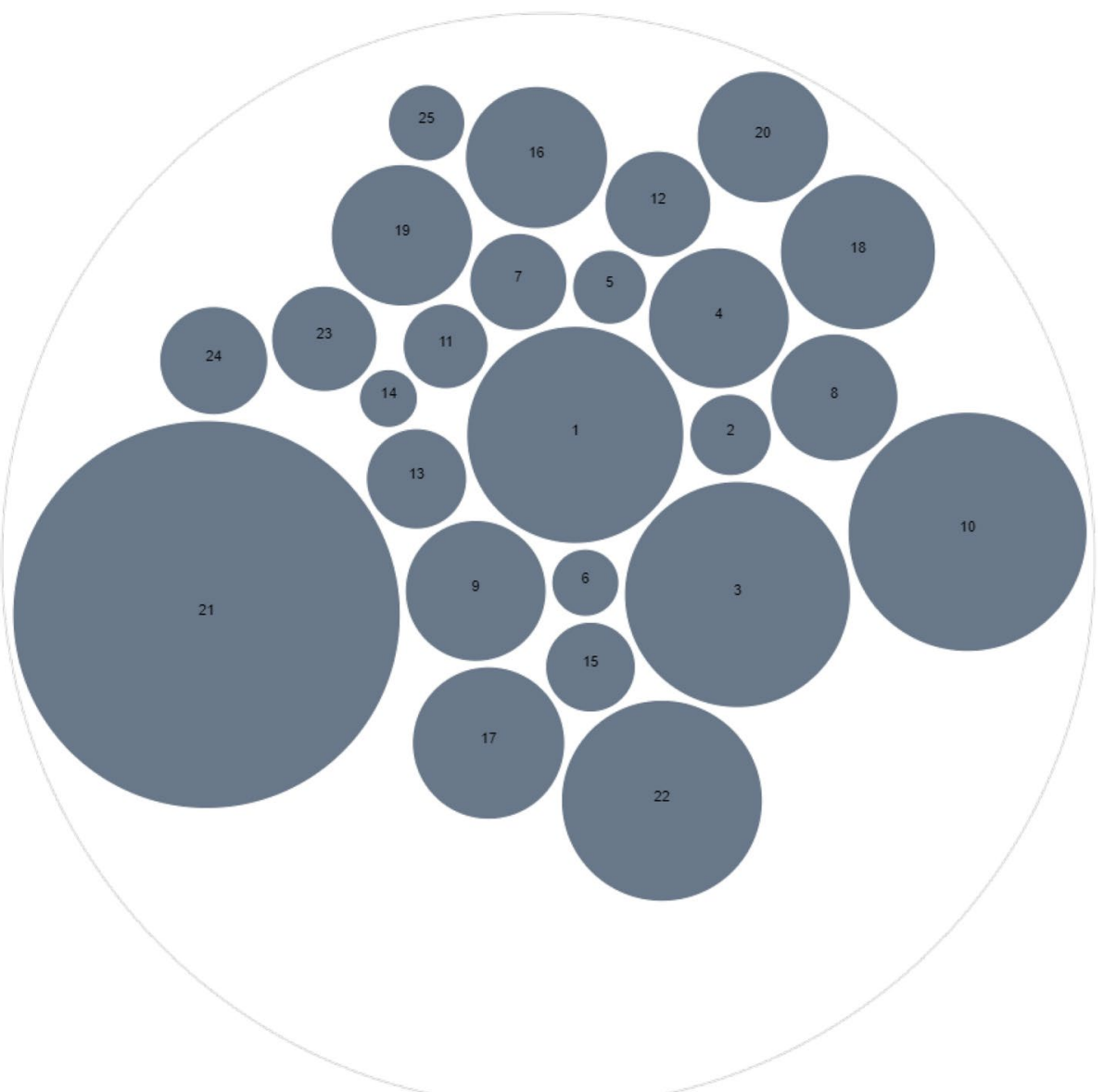

Table 6 Computation of $\rho_{W A}$

\begin{tabular}{|c|c|c|c|}
\hline Id & Error & Contrast & $\rho_{W A}$ \\
\hline 1 & 60 & 224 & 82.4 \\
\hline 2 & 11 & 4 & 11.4 \\
\hline 3 & 87 & 23 & 89.3 \\
\hline 4 & 34 & 5 & 34.5 \\
\hline 5 & 9 & 4 & 9.4 \\
\hline 6 & 7 & 7 & 7.7 \\
\hline 7 & 15 & 13 & 16.3 \\
\hline 8 & 24 & 41 & 28.1 \\
\hline 9 & 34 & 5 & 34.5 \\
\hline 10 & 93 & 70 & 100 \\
\hline 11 & 12 & 4 & 12.4 \\
\hline 12 & 19 & 4 & 19.4 \\
\hline 13 & 17 & 4 & 17.4 \\
\hline 14 & 4 & 17 & 5.7 \\
\hline 15 & 13 & 9 & 13.9 \\
\hline 16 & 28 & 71 & 35.1 \\
\hline 17 & 38 & 24 & 40.4 \\
\hline 18 & 41 & 9 & 41.9 \\
\hline 19 & 30 & 48 & 34.8 \\
\hline 20 & 28 & 20 & 30 \\
\hline 21 & 263 & 9 & 263.9 \\
\hline 22 & 69 & 16 & 70.6 \\
\hline 23 & 17 & 22 & 19.2 \\
\hline 24 & 17 & 32 & 20.2 \\
\hline 25 & 10 & 0 & 10 \\
\hline
\end{tabular}

Table 7 Computation of accessibility of barrier count $\rho$

\begin{tabular}{lll}
\hline ID & URL & Score \\
\hline 1 & https://www.iisc.ac.in/ & 45.18 \\
2 & https://www.jnu.ac.in/main/ & 27.98 \\
3 & https://www.bhu.ac.in/ & 721.63 \\
4 & https://www.amrita.edu/ & 36.375 \\
5 & http://www.jaduniv.edu.in/ & 13.905 \\
6 & https://www.uohyd.ac.in/ & 23.17 \\
7 & https://www.caluniv.ac.in/ & 20.57 \\
8 & https://manipal.edu/mu.html & 45.175 \\
9 & http://www.unipune.ac.in/ & 32.98 \\
10 & https://www.jmi.ac.in/ & 84.29 \\
11 & http://www.du.ac.in/du/ & 259.7 \\
12 & https://www.annauniv.edu/ & 19.44 \\
13 & https://www.b-u.ac.in/ & 30.85 \\
14 & http://www.hbni.ac.in// & 8.95 \\
15 & https://www.bits-pilani.ac.in/ & 19.375 \\
16 & https://vit.ac.in/ & 44.335 \\
17 & https://www.amu.ac.in/ & 52.265 \\
18 & https://www.ictmumbai.edu.in/ & 208.95 \\
19 & https://www.andhrauniversity.edu.in/ & 72.595 \\
20 & https://www.soa.ac.in/ & 29 \\
22 & http://jamiahamdard.edu/ & 401.105 \\
23 & https://www.unom.ac.in// & 78.025 \\
\hline & https://www.keralauniversity.ac.in/ & 57.42 \\
& https://kiit.ac.in/ & 48.825 \\
24 & https://www.sastra.edu/ & 14.21 \\
\hline & &
\end{tabular}


Fig. 5 Circle packing chart of overall score $\rho$

- Readability level of these documents needs to be maintained in accordance with the levels that can be easily understood by the target audience;

- Before uploading the resources the default accessibility testing features of authoring tools shall be utilized to validate the accessibility.

The aforementioned suggestions shall enhance the accessibility of web pages for persons with disabilities. Though they are given here in the context of educational web pages, they shall be adapted for any web page that is targeted to have an universal accessibility.

\section{Conclusion and future directions}

This paper has presented the web accessibility analysis of educational websites in India. In this paper, a variable weight approach is presented to compute accessibility barrier count.

Two different approaches of computing the scores are presented through two algorithms. In both of these algorithms, a method to compute the accessibility barrier score is presented. Various components of the accessibility evaluation tools AChecker and WAVE are adopted to compute the score.
With a data set of the top twenty five Indian educational institutions website homepages, the accessibility barrier count $\rho_{A C}$ was computed which involved three components and a severity factor to scale down the weights based on the importance. Similarly, the accessibility barrier count component $\rho_{W A}$ was computed. These two component scores were utilized to build the integrated score.

In line with the feedback received from students with disabilities, various suggestions were presented to enhance the accessibility of web pages for persons with disabilities.

The future directions for this research work shall include the development of an accessibility score for multilingual web pages by incorporating various features specific to multilingual web pages. Incorporation of specific scores for various categories of persons with disabilities shall also be taken as a future enhancement.

The approach presented in this paper is aimed toward building awareness on web accessibility among the webmasters and web developers, particularly during the ongoing Covid-19 scenario, so that the information access needs of students with disabilities shall be satisfied in an efficient manner. 


\section{Declarations}

Conflict of interest The authors report no conflicts of interest.

\section{References}

1. Acosta-Vargas, P., Luján-Mora, S., Acosta, T., Salvador-Ullauri, L.: Toward a combined method for evaluation of web accessibility. In: International Conference on Information Theoretic Security, pp. 602-613. Springer (2018)

2. Acosta-Vargas, P., Ramos-Galarza, C., Salvador-Ullauri, L., Chanchí, G.E., Jadán-Guerrero, J.: Improve accessibility and visibility of selected university websites. In: International Conference on Applied Human Factors and Ergonomics, pp. 229-235. Springer (2020)

3. Ahmed, F., Borodin, Y., Puzis, Y., Ramakrishnan, I.: Why read if you can skim: towards enabling faster screen reading. In: Proceedings of the International Cross-Disciplinary Conference on Web Accessibility, pp. 1-10 (2012)

4. Aizpurua, A., Harper, S., Vigo, M.: Exploring the relationship between web accessibility and user experience. Int J Human Comput Stud 91, 13-23 (2016)

5. Akram, M., Sulaiman, R.B.: A systematic literature review to determine the web accessibility issues in Saudi Arabian university and government websites for disable people. Int J Adv Comput Sci Appl 8(6), (2017)

6. Alahmadi, T., Drew, S.: An evaluation of the accessibility of top-ranking university websites: Accessibility rates from 2005 to 2015. J Open Flexible Distance Learn 21(1), 7-24 (2017)

7. Arrue, M., Vigo, M.: Considering web accessibility in information retrieval systems. In: International Conference on Web Engineering, pp. 370-384. Springer (2007)

8. Bandeira, R., Lopes, R., Carriço, L.: Towards mobile web accessibility evaluation. Free and Open Source Software for Accessible Mainstream Applications (FOSS-AMA), colocated with ETAPS pp. 27-28 (2010)

9. Bigham, J.P.: Increasing web accessibility by automatically judging alternative text quality. In: Proceedings of the 12th International Conference on Intelligent User Interfaces, pp. 349-352 (2007)

10. Gambino, O., Pirrone, R., Di Giorgio, F.: Accessibility of the Italian institutional web pages: a survey on the compliance of the italian public administration web pages to the stanca act and its 22 technical requirements for web accessibility. Univ Access Inf Soc 15(2), 305-312 (2016)

11. Hasanuzzaman, F.M., Yang, X., Tian, Y.: Robust and effective component-based banknote recognition for the blind. IEEE Trans Syst Man Cybern Part C Appl Rev 42(6), 1021-1030 (2012)

12. Inal, Y., Rızvanoğlu, K., Yesilada, Y.: Web accessibility in turkey: awareness, understanding and practices of user experience professionals. Univ Access Inf Soc 18(2), 387-398 (2019)

13. Inan, F.A., Namin, A.S., Pogrund, R.L., Jones, K.S.: Internet use and cybersecurity concerns of individuals with visual impairments. J Educ Technol Soc 19(1), 28-40 (2016)

14. Ismail, A., Kuppusamy, K.: Accessibility of Indian universities' homepages: an exploratory study. J King Saud University Computer Inf Sci 30(2), 268-278 (2018)

15. Ismail, A., Kuppusamy, K.: Web accessibility investigation and identification of major issues of higher education websites with statistical measures: a case study of college websites. J King Saud Univ Comput Inf Sci (2019)

16. Ismail, A., Kuppusamy, K., Kumar, A., Ojha, P.K.: Connect the dots: accessibility, readability and site ranking-an investigation with reference to top ranked websites of government of india. J King Saud University Comput Inf Sci 31(4), 528-540 (2019)

17. Ismail, A., Kuppusamy, K., Paiva, S.: Accessibility analysis of higher education institution websites of Portugal. Univ Access Inf Soc pp. 1-16 (2019)

18. Kane, S.K., Shulman, J.A., Shockley, T.J., Ladner, R.E.: A web accessibility report card for top international university web sites. In: Proceedings of the 2007 International Cross-Disciplinary Conference on Web Accessibility (W4A), pp. 148-156 (2007)

19. Máñez-Carvajal, C., Cervera-Mérida, J.F., Fernández-Piqueras, R.: Web accessibility evaluation of top-ranking university web sites in Spain, Chile and Mexico. Univ Access Inf Society pp. 1-6 (2019)

20. Manzoor, M., Vimarlund, V.: Digital technologies for social inclusion of individuals with disabilities. Health Technol 8(5), 377-390 (2018)

21. Ojha, P.K., Ismail, A., Kuppusamy, K.: Perusal of readability with focus on web content understandability. J King Saud Univ Comput Inf Sci (2018)

22. Ojha, P.K., Ismail, A., Kuppusamy, K.: Readability assessmentcum-evaluation of government department websites of rajasthan. In: Proceedings of First International Conference on Smart System, Innovations and Computing, pp. 235-244. Springer (2018)

23. Panda, S., Chakravarty, R.: Evaluating the web accessibility of iit libraries: a study of web content accessibility guidelines. Perform Measure Metrics (2020)

24. Pantula, M., Kuppusamy, K.: A machine learning-based model to evaluate readability and assess grade level for the web pages. Comput J (2020)

25. Rezae, M., Chen, N., McMeekin, D., Tan, T., Krishna, A., Lee, H.: The evaluation of a mobile user interface for people on the autism spectrum: an eye movement study. Int J Human Comput Stud p. $102462(2020)$

26. Rodriguez, G., Pérez, J., Cueva, S., Torres, R.: A framework for improving web accessibility and usability of open course ware sites. Comput Educ 109, 197-215 (2017)

27. Ross, A.S., Zhang, X., Fogarty, J., Wobbrock, J.O.: An epidemiology-inspired large-scale analysis of android app accessibility. ACM Trans Access Comput 13(1) (2020). https://doi.org/10.1145/ 3348797

28. Sinha, P.: Web accessibility analysis of government tourism websites in india. In: Proceedings of 3rd International Conference on Internet of Things and Connected Technologies (ICIoTCT), pp. 26-27 (2018)

29. Vigo, M., Aizpurua, A., Arrue, M., Abascal, J.: Evaluating web accessibility for specific mobile devices. In: Proceedings of the 2008 international cross-disciplinary conference on Web accessibility (W4A), pp. 65-72 (2008)

30. Vollenwyder, B., Iten, G.H., Brühlmann, F., Opwis, K., Mekler, E.D.: Salient beliefs influencing the intention to consider web accessibility. Comput Human Behav 92, 352-360 (2019)

31. Yan, S., Ramachandran, P.G.: The current status of accessibility in mobile apps. ACM Trans Access Comput 12(1) (2019). https:// doi.org/10.1145/3300176

32. Yerlikaya, Z., Durdu, P.O.: Evaluation of accessibility of university websites: A case from turkey. In: International Conference on Human-Computer Interaction, pp. 663-668. Springer (2017)

33. Yi, Y.J.: Web accessibility of healthcare web sites of Korean government and public agencies: a user test for persons with visual impairment. Univ Access Inf Soc 19(1), 41-56 (2020)

Publisher's Note Springer Nature remains neutral with regard to jurisdictional claims in published maps and institutional affiliations. 